\title{
The Spirit of Science: Attribute and Structural Model
}

\author{
Jian Zhou ${ }^{1,2^{\star}}$, Jian'er Yu ${ }^{1,2}$, Jianxia Qiu', Yuanyuan Zhou ${ }^{1}$ \\ 1 Second People's Hospital,Shanwei,Guangdong,516600, China \\ 2 Shanwei Branch of the Medicine College of Shantou University, shanwei, Guangdong, \\ 516600, China \\ Jian Zhou: j6789@163.com \\ Jian’er Yu: gdyujer@21cn.com \\ Jianxia Qiu: zhou6789@21cn.com \\ Yuanyuan Zhou: yuanyuanz@21cn.com \\ *Correspondence: j6789@163.com; Tel.:+86-660-339-5633
}

\begin{abstract}
Spirit of science is one of the important components of science education theory. It not only directly affects the level of science education, but also indirectly affects the selection, education and evaluation of scientific researchers, and the development of science and technology in a country or region. Although more than a century ago, the researchers began to discuss the topic of spirit of science. However, to date, the research of the definition, attribute, structural model and its characteristics of the spirit of science has not yet made a breakthrough. Based on the detailed literature review, the related theoretical analysis and the research of the structural model of the spirit of science, this paper puts forward the new definition, the attribute and the establishment of the structural model of the spirit of science, and analyzes the match the situation from new structural model of the spirit of science and the scientific nature published by the American Society for the Advancement of Science. The results of this study are of great significance for raising the level of scientific education and cultivating future scientific researchers, enhancing their motivation and skills in innovation in scientific research and promoting the development of future scientific undertakings.
\end{abstract}

Keywords: spirit of science; definition; attribute; model; characteristics 


\section{Introduction}

Generally speaking, there are three ways to express the spirit of science. It comprises Spirit of Science (SoS), scientific spirit and scientific mind. Williamson [25], Beveridge [2], Goran [7], Jenkins [9] and Porter [17] also used "the SoS". Thus, in order to facilitate the discussion, this paper uses the first expression. As we all know, SoS is one of the important components of science education theory. Obviously, if SoS as a complete theoretical knowledge from the science education theory, then at least able to answer the following questions: (1) what is the definition of the SoS? (2) what is the attribute of the SoS? (3) what is the structural model of the SoS? (4) what are the characteristics of the SoS? For the SoS of the discussion, as early as a hundred years ago began. Snowden [19] published a paper in The Biblical World. The title of paper is The Scientific Spirit in Theological Study and Teaching. About the definition of the SoS, he put forward a fuzzy definitions. His study also described a few content for the attribute of the SoS. In addition, Miller [14], Nature editor [15], Gentralissimo [6], Educational Policies Commission [4], McLaren [12], Lefkowitz [11] , American Association for the Advancement of Science Americans [1], Visser [22], Cai De-cheng [3], Qin Yuan-hai [18], Lee [10] were researched for the attribute of SoS and they have published a few different opinions. About the structural model of the SoS, Merton [13] Visser [22],Wang Bing [24], Su Dan [20] published a few papers and put forwarded a few different view. However, they are mostly studied from different perspective, in connection with one or two aspects (such as values, or cognitive preference or habitual behavior) put forward some new viewpoints. Therefore, these results are lack of systematic and integrity. For the characteristics of the SoS, it is no systematic reports were found.

Unfortunately, for the four problems mentioned above, to date, the answers to these questions are still incomplete, unclear and imprecise. The existence of this situation will inevitably reduce the effectiveness of science education, because this theoretical knowledge, in which are vague, lack of completeness and the structure of confusion, will inevitably lead to the audience difficulties to understand, accept, identify and practice. This study committed to updating and perfecting the theoretical system of the SoS. This theory of the SoS has some important and potential value in the following: (1) to perfect the theoretical system of science education, (2) to enhance the effect of science education, (3) to enhance the scientific literacy of researchers and research skills,(4) to help researchers to obtain better results, (5) as a tool for the screening and evaluation of researchers.

\section{Analysis and argument}

\subsection{Analysis of the words of the SoS}

Before discussing the definition of the SoS, it is necessary to do some analysis on the two words of "science" and "spirit". About the explaining of science, Hornby [8] said:

"organized knowledge, esp when obtained by observation and testing of facts, about physical world, natural laws and society, study leading to such knowledge (p.1342) ." For the explaining of spirit, Hornby said: "person's mind or feeling as distinct from his body (p.1465). "

From this explanation, we can see that "science" is only representative of organized 
knowledge and "spirit" is the mind or feeling from person's brain. Thus "science" can not take as the carrier of "spirit" and this carrier must be the person. Therefore in this place "science" ought to change the "scientists". Then the spirit of science also ought to change the spirit of scientists. Of course, according to custom and convenient reason, SoS can continue to be used for the synonym of "spirit of scientists".

\subsection{The definition of the SoS}

About the definition of the SoS, Snowden [19] wrote:

The scientific spirit first calls for definition, or at least for description; for spirit is atmospheric and elusive and always difficult of definition, refusing to be caught and caged within the hard and fast limits of verbal lines. Yet the phrase stands for a method and temper of study the nature of which is distinctly felt and is sharply contrasted with some other types of mind. (p.275)

Obviously, this definition is very vague. And the subsequent researchers either put forward some similar fuzzy definitions. In addition, in many author's (such as Williamson, Goran, Jenkins and Porter ) article, there is no mention this definition problem. Through literature review, referring to the some results of previous studies, combined with the principles and knowledge of psychology, sociology and history of science, this study put forward a new definition of the SoS. SoS is scientists show, in the work of research, a group of clustering characteristics from human values, personality traits, cognition preference and habitual behavior.

\subsection{The attribute of the SoS}

According to the new definition of the SoS, we can see it included a group of clustering characteristics. In other words, this group of clustering characteristics could be called the attribute of the SoS. About the attribute of the SoS, Snowden pointed out seek the truth, honesty, explore, kindness, withstand frustration and persevere. Miller [14] said: "What is the real 'Spirit of Science' ? Saint Paul says: 'Prove all things; hold fast that which is good'; and Saint Matthew adds: 'By their fruits ye shall know them.'” Professor I.P.Pavlov admonished his students, to engage in scientific research work must seek truth from facts, adhere to the study, observation, experiment, can not be satisfied with the data collection; to be modest, to keep the passion and devotion to science. Gentralissimo mentioned that scientific research not only to the pursuit of new knowledge, but also need the spirit of perseverance and the spirit of cooperation. Educational Policies Commission [4] listed seven values underlying science that are important for science education:

(1) longing to know and understand; (2) questioning all things; (3) search for data and their

attribute; (4) demand for verification; (5) respect for logic; (6)consideration of premises; and

(7)consideration of consequences.(p.15)

McLaren [12] said, "I would call the spirit of science. This is the quest for knowledge of the workings of nature, that kind of knowledge that Ziman describes as 'public' (Ziman, 1967) and 'reliable' (Ziman, 1968), subject to experimental testing.” Lefkowitz [11] also said:

what is the scientific spirit? ..... I would like to focus for a few moments on three elements of this scientific spirit: enthusiasm, creativity, and integrity...... Simply stated, it is a keenly felt sense of wonder and curiosity that translates into a genuine enthusiasm for even the faintest glimpses of 
new understanding.(p.375)

In Science for all Americans, American Association for the Advancement of Science Americans ${ }^{[1]}$ pointed out: (1) science demands evidence; (2) science is a blend of logic and imagination; (3) science explains and predicts; (4) scientists try to identify and avoid bias. Visser [22] wrote:

The scientific mind is a complex mindset. The following suggestions are offered as a starting point for the description of its multidimensional character: (1)The spirit of inquiry; (2)The spirit of collaboration; (3)The quest for beauty (harmony, parsimony, wholeness); (4)The desire to understand and do so profoundly; (5)The creative spirit; (6)The urge to be critical; (7)The spirit to transcend; (8)The spirit of building on prior knowledge; (9)The search for unity; (10)The building of the story of human knowledge and ability; (11)The spirit of construction. (p.6)

Cai De-cheng [3] considered that SoS contain "at least the following six elements: the objective basis, rational skepticism, pluralistic thinking, affirmative argument, the test of practice, generous incentives." Qin Yuan-hai [18] said: "scientists who is advocating the truth reality, seeking truth, perseverance, perseverance to explore, skeptical, dare to challenge, dare to innovate, stick to their selfless dedication, the sentiment, quality and behavior character." Lee [10] pointed out: (1) science is based on empirical evidence; (2) science relies on observation and inference; (3) both reasoning and imagination (creativity) are important in science; (4) scientists are not totally objective but try to avoid bias; (5) skepticism and criticism are critical in scientific thinking. For the study of the attribute of the SoS, the results of 12 researchers are listed in here (see Figure 1).

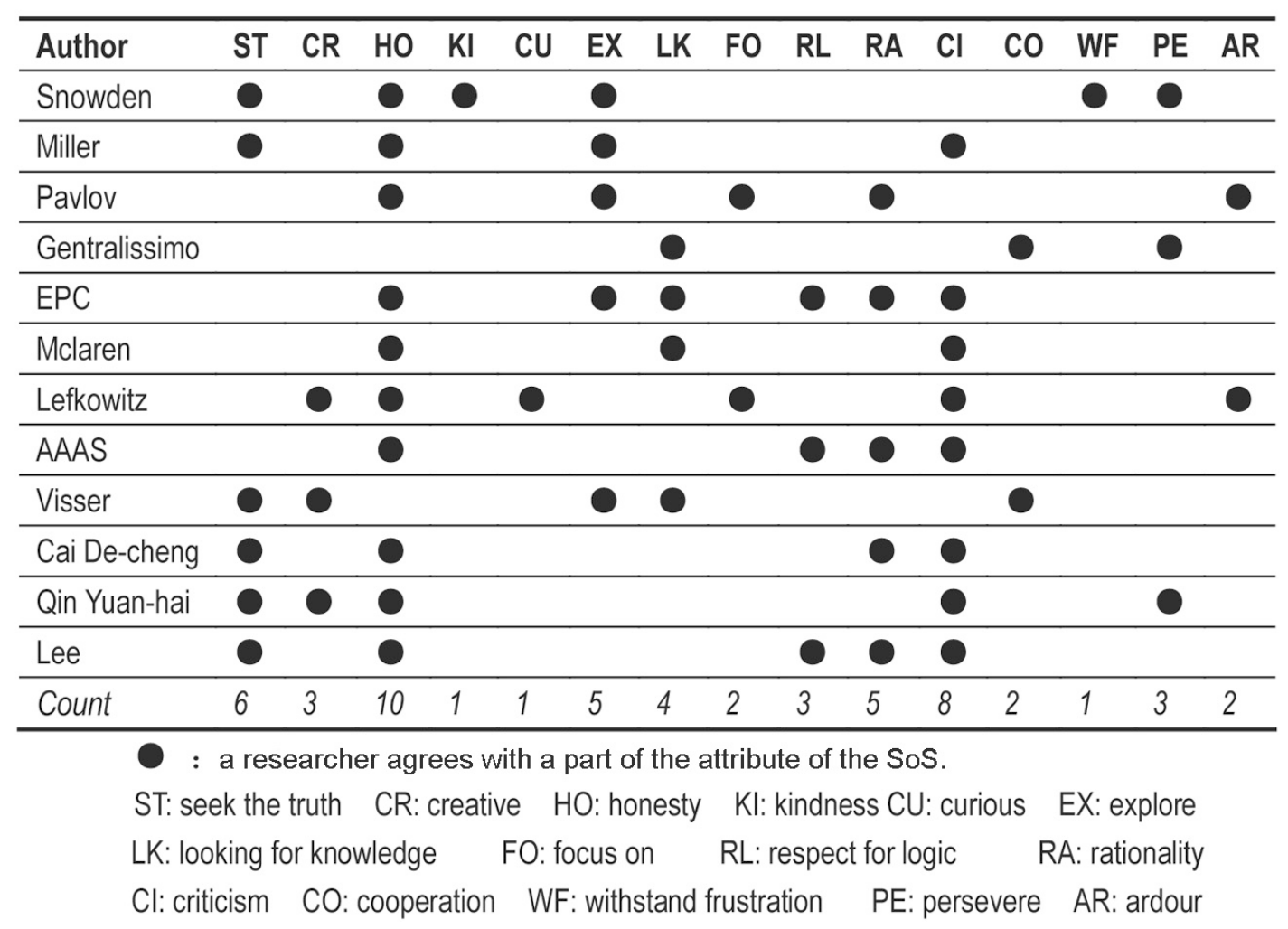

Figure 1. Summary graph of the of the attribute of the SoS. 
From Figure 1 we can see these researchers from different perspectives, put forward some the attribute of the SoS. These attributes have both the same and the dissimilarity. Therefore, for the attribute of the SoS, the results of previous studies are flawed, mainly due to the lack of systematic and complete. Referring to the results of previous studies, combined with the knowledge of pedagogy, psychology and the history of science, refer to the four dimensions of new definition of the SoS (include human values, personality traits, cognition preference and habitual behavior), proposed a complete the attribute of the SoS. The attribute of the SoS includes seek the truth, creative, honesty, kindness, curious, explore, looking for knowledge, calmly, focus on, respect for logic, rationality, criticism, enterprise, cooperation, withstand frustration and persevere. The explaining of the attribute of SoS is in the following. (1)Seek the truth: yearning for truth and the pursuit of truth. (2)Creative: the pursuit of innovation and the pursuit of discovery. (3)Honesty: respect for the objective and the pursuit of facts. (4)Kindness: adhering to the kindness and justice. (5)Curiosity: keep interest and the development of curiosity. (6)Explore: the courage to explore and constantly seeking. (7)Looking for knowledge: discover knowledge and the pursuit of wisdom. (8)Calmly: keep calm and flexible response. (9)Focus on: concentrate on and continuous research. (10)Respect for logic: attention to the rule and grasp the logic. (11)Rationality: thoughtful and rational decision. (12)Criticism: repeated scrutiny and strictly questioned. (13)Enterprise: aggressive action and continuous to move forward. (14)Cooperation: mutual support and close cooperation. (15)Withstand frustration: calmly deal with and lessons learned. (16)Persevere: careful planning and long-term adherence.

For many researchers and scientists,W.I.B.Beveridge [2] wrote The Art of Scientific Investigation, is a classical works. In this book, a series of topics are discussed in detail. These topics include creative, honesty, kindness, curious, explore, focus on, respect for logic, rationality, criticism, enterprise, cooperation, withstand frustration and persevere. In discussing the exploration, Beveridge [2] pointed out:

Scientific observation of objects calls for the closest possible scrutiny, if necessary with the aid of a lens. The making of detailed notes and drawings is a valuable means of prompting one to observe accurately. This is the main reason for making students do drawings in practical classes. Sir MacFarlane Burnet has autopsied tens of thousands of mice in the course of his researches on influenza, but he examines the lungs of every mouse with a lens and makes a careful drawing of the lesions. In recording scientific observations one should always be as precise as possible.(p.104)

It can be seen that the topics of this book is quite consistent with the attribute of the SoS from this paper. About the seek the truth, Porter [17] also mentioned that the purpose of science includes the pursuit of truth.

\subsection{The structural model of the SoS}

For the structural model of the SoS, in The Normative Structure of Science, Merton [13] mention that SoS is a set of constraints of scientists of values and norms. Its comprised universal, public, without prejudice, organized skepticism. Visser [22] said:

The scientific mind comprises attitudes and skills - cognitive and meta-cognitive ones -that 
disposition people to question the facts and critically challenge the 'givenness' of any a priori knowledge and authority.(p.3)

Wang Bing [24] pointed out the structural model of the SoS included the values, pattern of behavior, behavior norm and scientific activities. Su Dan [20] also said:

SoS is a kind of ideal spirit temperament which is embodied by the scientific group's behavior standard, which includes many factors, such as scientific attitude, scientific method, scientific style and so on.(p.59)

The above studies show that the research for the structural model of the SoS is lack of integrity.

This study on the basis of previous studies, through theoretical analysis and modeling of analysis, a new structural model of the SoS is proposed. The model is composed four dimensions and two levels of structure. The four dimensions are values, personality traits, cognitive preferences and habitual behavior. The detail of the structural model of SoS (see Figure 2). In the following, the structural model of the SoS is abbreviated to as MSS.

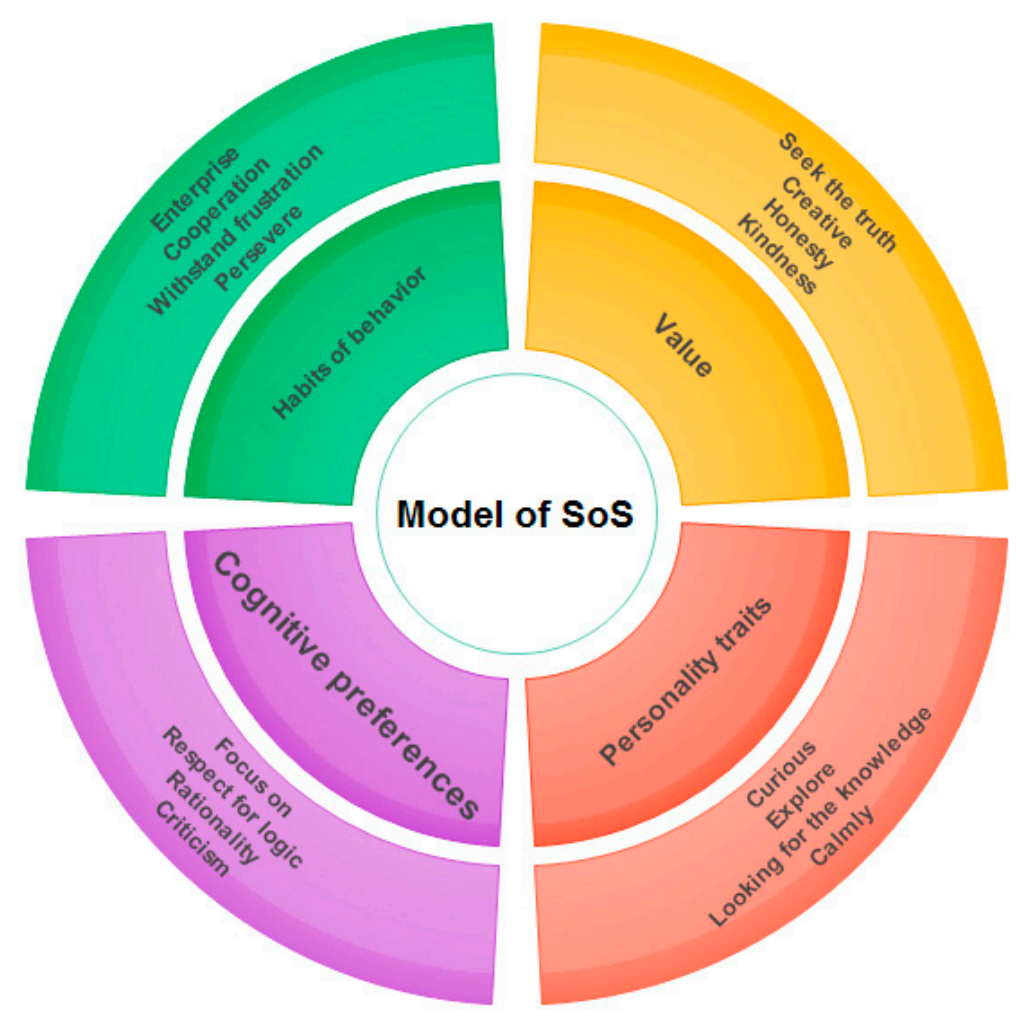

Figure 2. The structural model of SoS (MSS)

\subsection{The nature of science and the MSS}

The nature of science (NoS) is also one of important context in the theories of scientific education. American Association for the Advancement of Science Americans published Science for All Americans [1] and expounded the context of NoS and the value of NoS. 
Lee made systematic study for NoS and to obtained good results. Torres \& Vasconcelos [21] wrote:

Developing students' understanding of NoS is now widely recognized as a crucial element of scientific literacy and one of the central goals of science education. Research on teaching and learning NoS has also become one of the central areas of science education research.(p.792)

NoS Statements in U.S. National-Level Documents comprised 13 clauses. After careful comparison and analysis, we find that these clauses is very similar to the 16 points from the attribute of the SoS in our study. These 16 points also is the structural element of second level from the MSS in our study. In other words, the MSS and the NoS is matching (see Figure 3). This matching also confirms the scientific nature, reliability and value of our study results from another perspective.

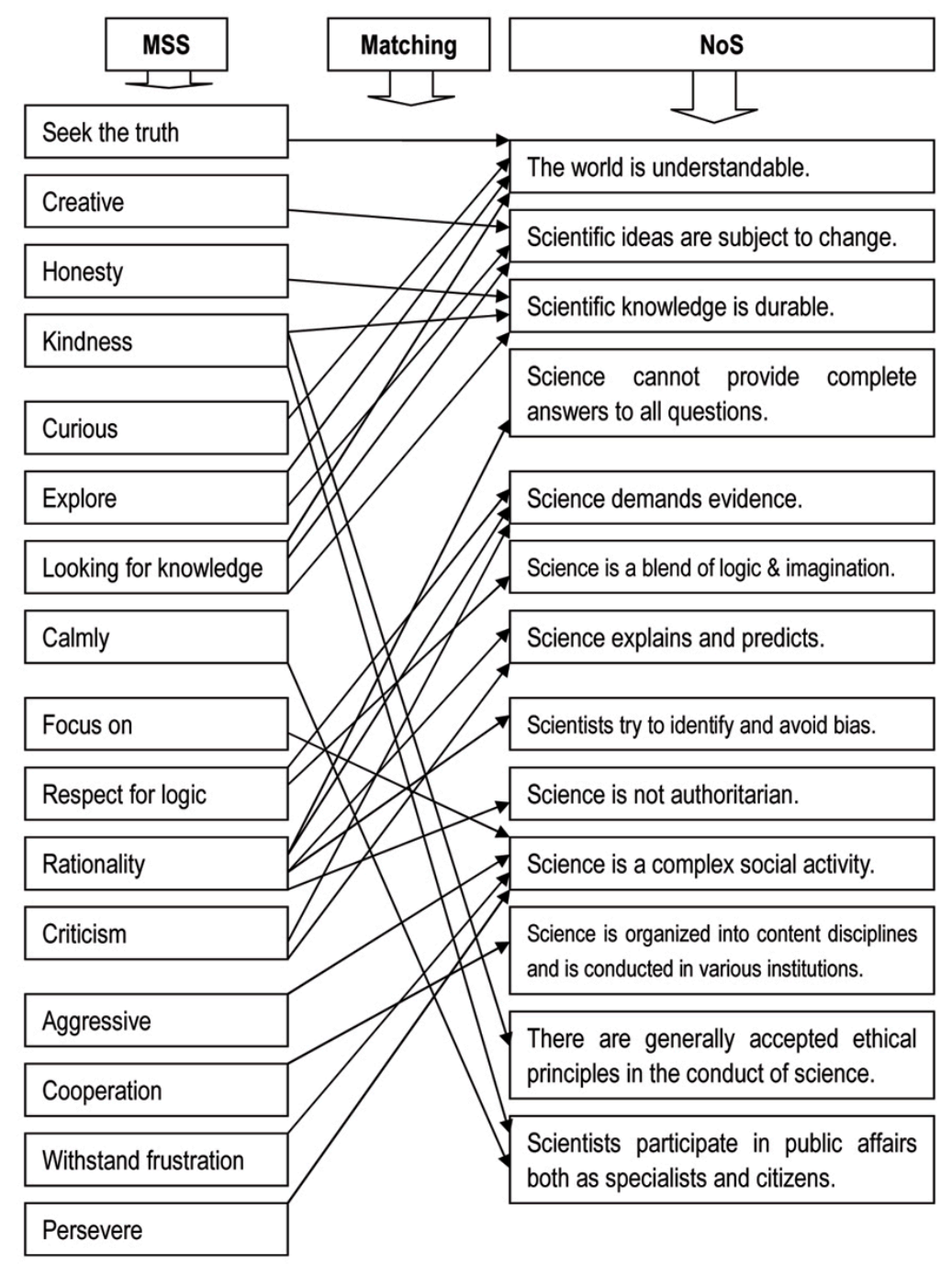

MSS originate from this research for the structural model of SoS.

NoS originate from Science for all Americans of AAAS (1990)

$\rightarrow$ : From MSS match to NoS.

Figure 3. A map of the matching situation from MSS \& NoS 


\subsection{The characteristics of the SoS}

For the characteristics of the SoS, in here a more appropriate vocabulary is the characteristics of the MSS. The characteristics of the MSS include some rule in the following. (1) From the above analysis, it is to know that MSS not only includes some psychological idiosyncrasy caused by human genetic, but also covers the human character restricted by acquired environmental. (2) For the psychological idiosyncrasy from MSS, it need to the starting from human boyhood and takes a lot of training, education, and exercise. If not, it is more difficult for adults to learn and to master these idiosyncrasies. (3) Some of the idiosyncrasy and character of MSS can be enhanced and strengthened through the education and exercise. (4) For the idiosyncrasy and character of each researcher, it's the width and depth of coverage is different. (5) For each researcher, he/she have the idiosyncrasy and character is the more the better within the framework of MSS. (6) For a researcher, if he/she have the more of idiosyncrasy and character, then their chance of success is greater in their science research. (7) If he/she is famine of idiosyncrasy and character, then he/she is not suitable for science research.

\section{Conclusion}

In 1872, in the discussion of cooperation in science research, Williamson [25] point out:

The conclusions to which these views lead me are very simple ones. The complex problems of paleophytology require harmonious and trustful cooperation amongst observers if truth is to be discovered. Let us supply this in the spirit of cordial fellow-labourers, and not as rivals in pursuit of a fleeting reputation which cannot be shared with others.(p.476)

The next one hundred and thirty years, some researchers (such as Snowden, EPC, AAAS, Lefkowitz, Visser, Qin Yuan-hai and Lee) pay attention to the theme of the SoS, some papers and books was published. However, most of their study is not specifically the SoS research project, but in the nature of scientific research, science education, scientific attitude, scientific method and other topics, occasionally involve the content of SoS. Gauld [5] said: "It is difficult to find any reference in science education literature to studies of the psychology of scientists, of sociological research into the nature of the ethos of science." So, to date, for research on the definition, the attribute, the structure model and characteristics of SoS, still lack a breakthrough. This situation is unfavorable for the progress in the science education and scientific research.

In order to promote the research of SoS, we based on the results of previous studies on the review, combined with the theory of science education, psychology, knowledge and principle of sociology and history of science, through theoretical analysis and practical experience analysis, carried out a systematic study on SoS。(1) Under the inspiration of Snowden et al., we put forward a new definition of the SoS, which has the advantages of completeness, accuracy and standardization compared with previous studies. (2) On the basis of research results from many researchers, summarized, adjust and improve the specific attribute of the SoS, summarized as to 16 points. The compared with previous studies, abandon the rare elements, adds some new elements, which reflects the system and integrity. About the attribute of criticism, Pollak [16] point out:

Now, if everything in science is ultimately rooted in experience, we can make the following assertion: The basic attitude of science is "do not believe it." The appropriate attitude for a scientist 
or science student is the attitude of doubt. (p.517)

For the attribute of honesty, Pollak [16] also said:

Scientific knowledge is based on evidence, not authority. Knowledge accepted on authority is belief. Knowledge based on evidence is experiential. Scientific evidence is often obtained by experiment, which we notice has the same root as the word experience. (p.517)

For the attribute of create, Pollak [16] wrote:

Nobel Prizes are awarded to people who did not believe it. No one ever won a Nobel Prize for providing evidence that supported an established theory. Nobel Prizes are awarded to people who find or clear up something outside of, or contradictory to, the conventional wisdom. That is how scientific progress is made $\mathrm{m}$ by challenging conventional wisdom; by putting it to the test under more and more extreme conditions. (p.517)

For the attribute of criticism, Wagner [23] said: "Third, students should be directed to acquire the dual properties of having a critical spirit, namely, being a critical thinker and having an interest in approaching competing claims critically."

From here we see that the opinion of ours, in some respects, is consistent with other scientist's opinion. (3) The related research in the past, involves the research of model of the SoS is relatively rare, the study of Visser and Lee inspire our study, on the basis of our results, to put forward a complete and practical the MSS. In the MSS, the opinion of Beveridge, the opinion of Educational Policies Commission and the opinion of American Association for the Advancement of Science Americans got expression. About the opinion of Educational Policies Commission, Goran [7] hold a positive attitude and he said:

Educational Policies Commission of the National Education Association and the American Association of School Administrators, in a pamphlet (1966) "Education and the Spirit of Science," urged that the spirit of science be a universal educational objective...... It listed and described longing to know and to understand, questioning of all things, search for data and their meaning, demand for verification, respect for logic, consideration of premises, and consideration of consequences. ..... the list of the Educational Policies Commission is close to the consensus.(p.322)

Thus it can be seen that our study is the inheritance and development of the previous study results. (4) We also analyze and summarize the characteristics of the model of the SoS, and put forward the 7 characteristics, so as to improve the system theory of the model of SoS.

The results of our study, especially the MSS model, show the positive significance in the following aspects. (1) Enrich the specific content of science education, to update and improve science education theory; (2) Help science teachers and science communication workers to enhance the level of science education. (3) To enhance students' acceptability for knowledge of science education, so as to improve the effect of science education. (4) To guide researchers to improve their scientific literacy, and enhance the power of scientific research. (5) To assist researchers to enhance the efficiency of research, more research achievements have been obtained. (6) Can be used as a selection of researchers, evaluation reference tool. (7) Can be expected, indirectly promote the development of the science and technology in a national or regional level.

Of course, our research is only the result of theoretical research, although from the 
scientific principle analysis of the results of this study can be self consistent, but also to need the verification from science education and scientific research in future.

Disclosure statement: No potential conflict of interest was reported by the authors.

Acknowledgments: As the first author of this article, I would also like to thank Mr. Xi Mingchuan for retrieving some of the research materials for me. At the same time, I also thank Xi Dakun for bringing me a happy time after my research work.

\section{Reference}

1. American Association for the Advancement of Science Americans (AAAS). Science for all Americans. New York: Oxford University Press, 1990.

2. Beveridge,W.I.B. The Art of Scientific Investigation, New York: First Published in the United States of America, 1957.

3. Cai De-cheng. Harmony with Scientific Spirit and Humanistic Spirit, Democracy and Science, 12-14, 2003.(in Chinese).

4. Educational Policies Commission, Education and the spirit of science. Washington, D. C.: National Education Association, 1966.

5. Gauld, C. The Scientific Attitude and Science Education: A Critical Reappraisal, Science Education, 66(1): 109-121,1982.

6. Gentralissimo \& Chiang Kai-shek. The Way and Spirit of Science, Nature, (8), 180-182, 1943.

7. Goran,M. How to Acquire the Spirit of Science, Improving College and University Teaching, Vol. 20, No. 4, p. 322-324,1972.

8. Hornby, A.S. Oxford Advanced Learner's English-Chinese Directory (4 Edition),Beijing: The Commercial Press,p1342,p1465,1997.

9. Jenkins, E. W. Science Education: A Structure Without Foundations?, Studies in Science Education, 3, p.138-142,1976.

10. Lee, Young-hee. A Proposal of Inclusive Framework of the Nature of Science (NOS) Based on the 4 Themes of Scientific Literacy for K-12 School Science, J Korea Assoc. Sci. Edu, Vol. 33, No. 3(5), pp. 553-568, 2013.

11. Lefkowitz, R.J. The Spirit of Science, J. Clin. Invest. 82(8), 375-378,1988.

12. McLaern, D. S. The spirit of science: a threat to medicine, Medical Education, 14, 225-226, 1980.

13. Merton, R.K. Normative structure of Science, Scientific and philosophical research, Beijing: Journal of Dialectics of Nature, 4(C),121-122, 1982. (in Chinese).

14. Miller, Dayton C. The Spirit and Service of Science, Science, (10), 297-299,1936.

15. Nature editor, Pavlov and the Spirit of Science, Nature, (4), 572,1936.

16. Pollak,V.L. Science Education-I: The Spirit of Science, Journal of Science Education and Technology, VoL 2, No. 4, 513-519,1993.

17. Porter, J.E. The Spirit(s) of Science: Paradoxical Positivism as Religious Discourse among Spiritualists, Science as Culture, 14, 1-21, 2005.

18. Qin Yuan-hai. On scientific spirit, Fudan University, 2006. (in Chinese).

19. Snowden, J. H. The Scientific Spirit in Theological Study and Teaching, The Biblical World, 
Vol.

49, No. 5 (May), 275-280,1917.

20. Su Dan. On the integration of scientific spirit and humanistic spirit, Journal of Academic Exchange, 1, 59-63, 2013. (in Chinese).

21. Torres, J., Vasconcelos, C.. Developing prospective science teachers 'views of nature of science: The scientific models. Conference Paper, April. 2016). See at: http://www.researchgate.net/publication/301647346.

22. Visser,J. The Scientific Mind in Context, Learning Development Institute, August 25, 2000.

23. Wagner,P.A. The Nature of Paradigmatic Shifts and the Goals of Science Education, Science Education, 67(5): 605-613,1983.

24. Wang Bing. Revelation of Scientific Spiri, Shanghai: Shanghai Science Popularization Press ,2005. (in Chinese).

25. Williamson,W.C. The Spirit of Scientific Controversy, Nature, (10), 475-476. 1872. 